\title{
Cancerogenesis and Polymyalgia Rheumatica
}

\section{Manzo C*}

Internal Medicine department, Chief of Geriatric Rheumatologic Outpatient Clinic, Mariano Lauro hospital, Sant'Agnello, Naples, Italy

${ }^{*}$ Corresponding author: Ciro Manzo, Internal Medicine department, Chief of Geriatric Rheumatologic Outpatient Clinic, Mariano Lauro hospital, Sant'Agnello, Naples, Italy, Tel: +39. 3389436790; Fax: +39.0815331449; E-mail: cirmanzo@libero.it

Received date: May 06, 2016; Accepted date: May 25, 2016; Published date: May 27, 2016

Copyright: (c) Manzo C. This is an open-access article distributed under the terms of the Creative Commons Attribution License, which permits unrestricted use, distribution, and reproduction in any medium, provided the original author and source are credited.

\begin{abstract}
Polymyalgia rheumatica (PMR) is considered the commonest inflammatory rheumatic disease in the elderly. The presence of constitutional symptoms such as fatigue, malaise, anorexia, weight loss and fever are common (in association with the typical PMR manifestations) and their association with very elevated inflammatory markers (for example erythrocyte sedimentation rate-ESR> $100 \mathrm{~mm} /$ hour or high C-reactive protein) may raise suspicion of a neoplasm. On the other hand, the relationship between PMR and cancer is still complex and data available from literature are contradictory. The association (or not) with giant-cell arteritis (GCA), the cumulative dosage of corticosteroids, the serum levels of C-reactive protein, the presence or not of RS3PE syndrome can represent important variables. In this review we perform a systematic electronic search of Medline and PubMed for evaluation of relationship between cancer and PMR, and present the more significant data.
\end{abstract}

Keywords: Cancerogenesis; Polymyalgia rheumatica; C-reactive protein; RS3PE syndrome; Corticosteroid therapy; Elderly patient

\section{Introduction}

Polymyalgia Rheumatica (PMR) is considered the most frequent inflammatory rheumatic disease in the elderly [1-3]. Classic symptoms are bilateral pain, aching and stiffness in the shoulders, pelvic girdle and neck, usually at sudden onset. In most cases the patient remembers the exact day when these symptoms have appeared [4]. As opposed to the symptoms of osteoarthritis, the stiffness and pain tend to be bilateral or symmetric and improve with activity; so, they are increased at morning awakening and tend to decrease during the course of the day. The dramatic response to low-dose corticosteroid treatment is characteristic and it has been an important diagnostic criterion until 2012. It is well-known that in some patients it may be necessary to change the glucocorticoid initially used with a different one at equivalent dosage to obtain an effective response. In 2012, a European League Against Rheumatism/American College of Rheumatology collaborative initiative [5] have proposed new classification criteria for PMR in which the response to corticosteroid therapy has been replaced by the US evaluation of the scapular and pelvic girdle.

Giant-cell arteritis (GCA) is the disease most commonly associated with PMR. Clinically, 40-60\% of patients with GCA have PMR symptoms at diagnosis while $16-21 \%$ of patients with PMR develop GCA [6].

Finally, a subset of patients with PMR has swelling and pitting edema of the hands and feet due to tenosynovitis, so called remitting seronegative symmetrical synovitis with pitting edema syndromeRS3PE syndrome [7]: this association can be observed up to $10 \%$ of patients $[8,9]$.

Constitutional symptoms such as fatigue, malaise, anorexia, weight loss and fever are also common in PMR patients and their association with raised inflammatory markers can realize, in some cases, a diagnostic challenge with neoplasias [10]. The relationship between cancerogenesis and PMR is still complex and intricate, and the possibility that PMR can be a paraneoplastic syndrome [11] or may favor the onset of a tumor is still debated.

\section{Aim}

To evaluate the relationship between cancer and PMR

\section{Materials and Methods}

We perform a systematic electronic search of Medline and PubMed for evaluation of relationship between cancer and PMR, and present the more significant data. Some personal contributions were also considered.

\section{Results}

\section{Carcinogenesis, PMR and GCA}

Some studies have evaluated this question. Only three institutional database studies are present in literature until today, according to our knowledge. Two of these database studies have suggested increased risk of cancer particularly in the first year of diagnosis. In particular, a data-base study from Sweden examined 35,928 patients following hospitalization for PMR and/or GCA in order to evaluated the overall and specific cancer risks and found a marginal increase in the incidence of cancer compared with the general population (standardized incidence ratio 1.19; 95\% confidence interval 1.06-1.23). However, when evaluating malignancy risk in the first year after diagnosis of PMR (or GCA), the standardized incidence ratio was 2.26 (95\% confidence interval 2.10-2.42). However for specific cancers, such as skin cancer and leukaemia, the increases were still significant for patients diagnosed later than 1 year after hospitalization, suggesting that these could be true associations. In general, a significant excess was also noted for stomach, lung, prostate, kidney, nervous system and endocrine gland tumours while decreased risk was noted for 
Page 2 of 4

endometrial cancer. The mechanisms of these associations were not established [12]. Another study utilized the UK General Practice Research Database (GPRD) and evaluated cancer risk in 2877 patients with PMR compared with age and sex-matched controls. All incident cases of PMR in the UK GPRD (1987-99), without pre-existing cancer or vascular disease and treated with corticosteroids were matched with up to five age, sex and GP practice patients without PMR ( $\mathrm{n}=9942)$. Over a median follow up of 7.8 years, $23.2 \%$ of patients with PMR developed cancer compared with $19.5 \%$ of controls. In the first 6 months after diagnosis, those with a PMR diagnosis were significantly more likely to receive a cancer diagnosis (adjusted HR (95\% CI): 1.69 (1.18 to 2.42). The number of events was small, but occurrences of prostate, blood, lymph nodes, female reproductive and nervous system cancers may be more common in those with PMR in the first six months after diagnosis. The authors were unable to determine whether the cancer incidence in PMR was different from controls, beyond this time point [13].

The emphasis in some of the studies present in literature is often on GCA, a condition that overlaps with PMR. Most of these studies were unable to definitively show whether or not there was an association between PMR/ GCA and cancer, although they have tended to be small and to focus on patients with GCA $[14,15]$. The association of GCA and its specific role represents one of the different critical elements. In the study proposed by Sara Muller et al. [13] although a proportion of those with PMR went on to develop the related condition of GCA, exclusion of these patients from the study sample did not change the final results.

Other studies have presented discordant conclusions. In our personal experience, for example, we found only 5 neoplasias in 200 elderly patients ( $>65$-years-old) with PMR (without GCA) we have consecutively observed at our rheumatologic outpatient clinic from 2002 to 2014. The minimum observation time for the appearance of an eventual cancer has been of 24 months from initial diagnosis of PMR. The lack of response to corticosteroid therapy (also kept changing the glucocorticoid with a second different glucocorticoid at equivalent doses) and/or the appearance of "suspect" signs or symptoms not consistent with PMR have accounted warning for finding eventual cancer. Three of these five patients had a RS3PE syndrome associated with PMR [16]. In another population-based cohort of 359 patients with PMR the cumulative incidence of malignancy at 10 years in patients with and without PMR was similar in the two groups (PMR $13.8 \pm 2.0$, control $13.1 \pm 2.0 ; \mathrm{p}$-value $=0.89)$ [17]. Likewise, in a Norwegian study published in 2002 ( $3^{\circ}$ institutional database series) no differences were found in frequencies or types of malignant neoplasms between patients with PMR or GCA and population controls [18].

\section{Carcinogenesis, PMR and RS3PE syndrome}

Remitting seronegative symmetrical synovitis with pitting edema (RS3PE) is an uncommon elderly-onset rheumatic picture descripted for the first time by Mc Carthy et al. [7] characterized by tenosynovitis of extensor tendons at the wrist and (less frequently) at the feet. Its removal occurs rapidly with low-dose corticosteroids and its relapse is extremely rare in the "benign" forms [9]. Both cancer and benign tumors have been descripted in association with RS3PE since 1985 and RS3PE can represent a neoplastic marker in elderly patients with rheumatic diseases (including, as noted above, PMR) up to $20 \%$ of cases $[19,20]$. The relationship between cancerogenesis and association PMR+RS3PE has been poorly considered in literature: for example, in a large case series recently published by Kaemacharva et al. a concurrent rheumatologic condition was reported only in 22 cases (6.65\%) and a concurrent PMR only in anecdotal cases [20]. In our experience, the association of RS3PE with PMR represents a strong neoplastic marker: the presence of this syndrome in patients with PMR - in fact - is associated with a very high risk for cancer (28.5\% PMR + RS3PE vs. only 2.04\% PMR without RS3PE) [16].

\section{Carcinogenesis, PMR and glucocorticoids}

As well known, systemic glucocorticoid use is the praxis in PMR. The fast response to low dosages of glucocorticoids is strongly characteristic of PMR and the effectiveness of prednisone $<20 \mathrm{mg} /$ day has more and more been highlighted [21]. We found data on glucocorticoids (in low dosages) and basal and squamous cell carcinoma limited to three older-age populations [22-25], only one observed a positive association [22]. An increased risk for squamous cell carcinoma of the skin (60-250 fold increase) and for basal cell carcinoma ( 10 fold increase) have been observed in some patients with conditions, such as organ transplantation, that require long-term, high-dose immunosuppression [26]. The specific association PMRglucorticoids- skin cancer has been not significantly evaluated. We can only speculate that since low dosages we usually use in PMR have not an immunosuppressive effectiveness, the risk for a skin cancer in PMR patients is very low or inexistent.

\section{Carcinogenesis and c-reactive protein}

C-reactive protein (CRP) is as well known a marker of acute-phase inflammatory response, produced mainly by hepatocytes. Its production is regulated by interleukin 6 (IL6). CRP and IL6 are characteristically high in PMR. CRP increases in PMR even in cases without ESR elevation [27,28]. CRP increases in a lot of diseases and in cancer, too. Several possible mechanisms have been proposed for the relationship between CRP and cancer: tumour growth can cause tissue inflammation and hence increase CRP levels; CRP could be an indicator of an immune response to tumour antigens; there is evidence that cancer cells can increase the production of inflammatory proteins, which could explain the high CRP concentrations in patients with cancer [29]. Some cancerous cells have been shown to express CRP [30] and cancer cell lines have been shown to secrete IL6 and IL8, which in turn induce as already said the production of CRP. The small number of prospective studies identified in literature regarding the relationship between CRP and cancer did not provide strong evidence for a causal role of CRP in malignancy, although there was some evidence that CRP could be related to colorectal cancer in particular [31,32]. In PMR patients, CRP levels dramatically decreased up to normalize in a few days after the start of corticosteroid therapy. The lowering of CRP is much more rapid than ESR (when as said it is high). On the other hand, persistently raised CRP has been suggested to correlate better with inflammation in PMR than ESR and may thus be better suited for use in definitions of remission and relapse $[33,34]$. In the clinical practice, persistently raised CRP in PMR is a strong warning for an infectious or neoplastic origin, expecially when it persists even after the change of the initial glucocorticoid with a different one, at equivalent doses.

\section{Discussion}

The possibility that PMR can represent a factor risk per cancer is still debated. The fact that the data available in the literature are greatly influenced by the design of the studies raises many questions. For 
Page 3 of 4

example, the conclusions of two database studies [12,13] are very different from the conclusion of cohort or population studies $[16,17]$. Caution should be used interpreting database studies since the diagnosis of PMR is not always confirmed by chart review and the possibility of misclassification is a concern. This is particularly true in PMR because there are no tests that are specific for the diagnosis of this disease and with honesty Sara Muller and collegues admit that "the increased rate of cancer within the first 6 months after diagnosis of PMR might occur for several reasons; the most obvious of which is misdiagnosis" [13]. Similarly in the manuscript of Ji et al [12], the fact that data were referred to hospitalized patients can represent an important bias because patients with PMR are usually followed and effectively treated in an outpatient clinic or at most at home. The use of low dosages of glucocorticoids seems to rule out an increased risk of developing non-melanoma skin cancer.

Certainly, the appearance of RS3PE syndrome greatly increases cancer risk. There is an almost unanimous agreement that RS3PE syndrome could represent a "form of rheumatic paraneoplastic syndrome" [35] but the neoplastic weight of the association between this syndrome with PMR has been poorly evaluated. As well-known, the lack of response to glucocorticoids in PMR is considered the main element in order to suspect a paraneoplastic syndrome and to activate the related investigations, even with patient's hospitalization. In the same way, a lack of normalization of CRP levels during glucocorticoid therapy must be representing a warning for neoplasia (or infectious event). The possibility that in the same patient with PMR the change of glucocorticoid initially used with a different one at equivalent doses may produce a recovery of efficacy (and CRP normalization) has to be highlighted in order to avoid diagnostic errors.

\section{Conclusion}

Cancerogenesis does not seem to increase in elderly patient with PMR, when we consider cohorts of patients followed in an outpatient clinic and not in hospital. Studies on multicenter cohorts are desirable. The lack of response to glucocorticoids is still the most important warning for cancer. The occurrence of RS3PE syndrome in PMR greatly increases the risk of cancer and the association RS3PE + polymyalgia rheumatica should be considered as a neoplastic marker.

\section{Acknowledgment}

I want to thank Dr. Maria Natale and Dr. Raffaele Cioffi for their precious cooperation in following all patients with PMR in the rheumatologic outpatient clinic of "Mariano Lauro" hospital.

\section{References}

1. Rooney PJ, Rooney J, Balint G, Balint P (2015) Polymyalgia rheumatica: 125 years of epidemiological progress? Scott Med J 60: 50-57.

2. Manzo C, Balduccelli M, Cappiello F, De Cesare M, Gargiulo L, et al. (2009) Epidemiology of polymyalgia rheumatica in the Massa Lubrense town. Trends Med 9: 101-105.

3. Muller S, Hider S, Helliwell T, Bailey J, Barraclough K, et al. (2012) The epidemiology of polymyalgia rheumatica in primary care: a research protocol. BMC Musculoskelet Disord 13: 102.

4. Manzo C (2009) La polimialgia reumatica: cosa è utile sapere per il geriatra territoriale ? Ger Extraosp VII: 9-11.

5. Dasgupta B, Cimmino MA, Maradit-Kremers H, Schimdt WA, Schirmer M, et al. (2012) 2012 Provisional classification criteria for polymyalgia rheumatica: a European League Against Rheumatism/American College of Rheumatology collaborative initiative. Ann Rheum Dis 71: 484-492.
6. Salvarani C, Cantini F, Hunder GG (2008) Polymyalgia rheumatica and giant-cell arteritis. Lancet 372: 234-245.

7. McCarty DJ, O'Duffy JD, Pearson L, Hunter JB (1985) Remitting seronegative symmetrical synovitis with pitting edema. RS3PE syndrome. JAMA 254: 2763-2767.

8. Salvarani C, Cantini F, Olivieri I (2000) Distal musculoskeletal manifestations in polymyalgia rheumatica. Clin Exp Rheumatol 18: S51-52.

9. Salvarani C, Cantini F, Olivieri I, Hunder GS (1999) Polymyalgia rheumatica: a disorder of extraarticular synovial structures? J Rheumatol 26: 517-521.

10. Manzo C, Natale M, Cappiello F (2008) Quanti anziani con Polimialgia Reumatica passano sotto gli occhi del medico del territorio? Ger Extraosp VI: 12-15.

11. Manzo C (2016) About a gastric neuroendocrine tumor presenting as polymyalgia rheumatica and macrocytic anemia. J Clin Case Rep (submitted for press).

12. Ji J, Liu X, Sundquist K, Sundquist J, Hemminki K (2010) Cancer risk in patients hospitalized with polymyalgia rheumatica and giant cell arteritis: a follow-up study in Sweden. Rheumatology (Oxford) 49: 1158-1163.

13. Muller S, Hider SL, Belcher J, Helliwell T, Mallen CD (2014) Is cancer associated with polymyalgia rheumatica? A cohort study in the General Practice Research Database. Ann Rheum Dis 73: 1769-1773.

14. Kermani TA, Schäfer VS, Crowson CS, Hunder GG, Gabriel SE, et al. (2010) Malignancy risk in patients with giant cell arteritis: a populationbased cohort study. Arthritis Care Res (Hoboken) 62: 149-154.

15. Haga HJ, Eide GE, Brun J, Johansen A, Langmark F (1993) Cancer in association with polymyalgia rheumatica and temporal arteritis. J Rheumatol 20: 1335-1339.

16. Manzo C, Natale M (2016) RS3PE syndrome in polymyalgia rheumatica: a neoplastic marker? Geriatrics 2016 (submitted for press);

17. Pfeifer EC, Crowson CS, Major BT, Matteson EL (2015) Polymyalgia Rheumatica and its Association with Cancer. Rheumatology (Sunnyvale) Suppl 6.

18. Myklebust G, Wilsgaard T, Jacobsen BK, Gran JT (2002) No increased frequency of malignant neoplasms in polymyalgia rheumatica and temporal arteritis. A prospective longitudinal study of 398 cases and matched population controls. J Rheumatol 29: 2143-2147.

19. Manger B, Schett G1 (2014) Paraneoplastic syndromes in rheumatology. Nat Rev Rheumatol 10: 662-670.

20. Kaemacharva P, Donato AA, Aryal MR, Ghimire S, Pathak R, et al. (2016) RS3PE revisited: a systematic review and meta-analysis of 331 cases. Clin Exp Rheumatol.

21. Healey LA (1984) Long-term follow-up of polymyalgia rheumatica: evidence for synovitis. Semin Arthritis Rheum 13: 322-328.

22. Baibergenova AT, Weinstock MA; VATTC Trial Group (2012) Oral prednisone use and risk of keratinocyte carcinoma in non-transplant population. The VATTC trial. J Eur Acad Dermatol Venereol 26: $1109-1115$.

23. Jensen AØ, Thomsen HF, Engebjerg MC, Olesen AB, Friis S, et al. (2009) Use of oral glucocorticoids and risk of skin cancer and non-Hodgkin's lymphoma: a population-based case-control study. Br J Cancer 100: 200-205.

24. Karagas MR, Cushing GL Jr, Greenberg ER, Mott LA, Spencer SK, et al. (2001) Non-melanoma skin cancers and glucocorticoid therapy. Br J Cancer 85: 683-686,

25. Sørensen HT, Mellemkjaer L, Nielsen GL, Baron JA, Olsen JH, et al. (2004) Skin cancers and non-hodgkin lymphoma among users of systemic glucocorticoids: a population-based cohort study. J Natl Cancer Inst 96: 709-711.

26. Walder BK, Robertson MR, Jeremy D (1971) Skin cancer and immunosuppression. Lancet 2: 1282-1283.

27. Martinez-Taboada VM, Blanco R, Rodriguez-Valverde V (2000) Polymyalgia rheumatica with normal erythrocyte sedimentation rate: clinical aspects. Clin Exp Rheumatol 18: S34-S37. 
28. Manzo C (2006) Polimialgia reumatica con VES bassa: considerazioni su di un caso clinico. Ger Extraosp 1-2: 82-83.

29. Heikkila K, Ebrahim S, Lawlo DA (2007) A systematic review of the association between circulating concentrations of $\mathrm{C}$ reactive protein and cancer. J Epidemiol Community Health 61: 824-832.

30. Nozoe T, Korenaga D, Futatsugi M, Saeki H, Maehara Y, et al. (2003) Immunohistochemical expression of $\mathrm{C}$ - reactive protein in squamous cell carcinoma of the esophagus - significance as a tumor marker. Cancer Lett 192: 89-95.

31. Garcia-Anguita A, Kakourou A, Tsilidis KK (2015) Biomarkers of Inflammation and Immune Function and Risk of Colorectal Cancer. Curr Colorectal Cancer Rep 11: 250-258.
32. Tsilidis KK, Branchini C, Guallar E, Helzlsouer KJ, Erlinger TP, et al. (2008) C-reactive protein and colorectal cancer risk: a systematic review of prospective studies. Int J Cancer 123: 1133-1140.

33. Salvarani C, Cantini F, Niccoli L, Macchioni P, Consonni D, et al. (2005) Acute-phase reactants and the risk of relapse/recurrence in polymyalgia rheumatica: a prospective followup study. Arthritis Rheum 53: 33-38.

34. Dejaco C, Duftner C, Cimmino MA, Dasgupta B, Salvarani C, et al. (2011) Definition of remission and relapse in polymyalgia rheumatica: data from a literature search compared with a Delphi-based expert consensus. Ann Rheum Dis 70: 447-453.

35. Li H, Altman RD, Yao Q (2015) RS3PE: Clinical and Research Development. Curr Rheumatol Rep 17: 49. 